\title{
Screening for and monitoring of cardio-metabolic risk factors in outpatients with severe mental illness in a primary care setting
}

\author{
JJ Ludwick, PP Oosthuizen \\ Department of Psychiatry, University of Stellenbosch, Cape Town, South Africa
}

\begin{abstract}
Objective: Recent findings suggest that premature death in patients with severe mental illness (SMI) can be attributed to the high comorbidity of cardio-metabolic disorders. This study investigated the prevalence and monitoring of some risk factors for cardio-metabolic disease in a cohort with SMI, compared to the general medical population. Method: 101 participants with SMI and 100 controls were recruited from a primary care clinic. Assessments of risk factors with standard clinical measurements were done after healthcare workers and patient-participants had completed the structured questionnaires. Clinical files were reviewed to determine frequency of monitoring of risk factors. Results: We found no differences between the groups in demographic variables. A similar prevalence of abnormal blood pressure (BP), increased Body Mass Index (BMI) and increased waist circumference was noted in both groups. Females in both groups were more likely to have an abnormal waist circumference. Patients with SMI were significantly less likely to have recordings of their weight or BP in their clinic file. Healthcare workers and patients with SMI were largely unaware of the increased risk of cardio-metabolic illness. Conclusion: This study suggests that patients with SMI received poorer health monitoring than other patients attending a primary care clinic and that both healthcare workers and patients were poorly informed about the increased risk of cardio-metabolic disorders in patients with SMI.
\end{abstract}

Key words: Mental illness; Comorbidity; Risk factors; Metabolic; Cardio-vascular

Received: 05-12-2008

Accepted: 12-01-2009

\section{Introduction}

Patients with severe mental illness (SMI) such as schizophrenia, bipolar disorder and major depressive disorder, have a life expectancy considerably shorter than that of the general population. In fact, patients with SMI die on average 20-30 years earlier than would be otherwise expected in a population of their peers. ${ }^{1}$ Clinicians are often unaware of this fact ${ }^{2}$, or if aware, consider the most likely causes to be "unnatural" ones, such as suicide. Recent evidence has however shown that most patients with SMI die of natural causes.1;3:4 Moreover, it has now been established that the vast majority of patients with SMI (50\% - 75\%) die as a result of cardiovascular disease. ${ }^{5}$ Cardiovascular disease is expected to become the single most important cause of death across the world within the next decade ${ }^{6-9}$, but its impact on

\section{Correspondence:}

Prof P Oosthuizen

Department of Psychiatry, PO Box 19063, Tygerberg, 7505

Cape Town, South Africa

email: pieto@sun.co.za the psychiatric population is even greater than in the general population. 1;3;4;10-12 The extremely high prevalence of metabolic syndrome and other cardio-vascular risk factors in patients with SMI has surprised many, and various causes for this have been proposed. 4;11:13-17 Among the suggested causes are lifestyle factors, 16 shared biological risk factors ${ }^{14}$, psychotropic medication ${ }^{15 ; 18-23}$ and factors associated with access to health care. ${ }^{24-30}$ Whatever the cause(s) may be, clinicians across disciplines should be aware of this comorbidity, so that it can be managed effectively. This is particularly true for clinicians working in primary care, as they are the most likely and frequent point of interaction between patients with SMI and the health care system.

Previous studies have however shown low levels of awareness of the comorbidity between SMI and cardiometabolic risk factors amongst clinicians and patients. ${ }^{2}$ However, most of the research and information on this topic emanates from the first world, with a significant lack of data from the developing world.

The aims of this study were firstly to determine the prevalence of risk factors for metabolic syndrome in a primary 
care population of patients with SMI versus those without SMI. Secondly, the awareness of this co-morbidity amongst healthcare workers and mentally ill patients was evaluated. Finally, differences in the monitoring of risk factors for cardiometabolic disorders for patients with SMI and patients without SMI were also assessed.

\section{Method}

\section{Sampling}

Participants for a single, cross sectional assessment were recruited from a community health clinic in the Western Cape, South Africa. This state-run clinic is situated in the Helderberg area and serves a working class population who depend largely on the public health services. All healthcare professionals working at the clinic were included. In addition, patient participants with SMI $(n=101)$ and patient participants without SMI ( $n=100$ ) from the general clinical population were also included. Participants from these two populations were selected by the researcher (JL), who approached every third patient visiting the clinic for mental health/illness purposes or for general reasons, until the required number of participants were included. Assessments were done over a period of 90 days.

Male and female patients that attended the community health clinic, able to provide informed consent and between the ages of 18 years and 65 years, inclusive of extremes, were considered for the study. Patients with known intellectual disability or unable to provide informed consent were not considered for the study.

\section{Procedure}

All health care professionals and trained health workers were asked to complete a brief questionnaire regarding their awareness of health risk factors in the general population and the psychiatric population, with specific reference to cardiometabolic disease. To prevent confounding by increased awareness due to study procedures, this part of the study was performed on the last working day before the patient participants' assessment started.

Every patient participant's blood pressure, weight, height and waist circumference were measured, using standard clinical methods. These measures, as well as the patient's known diagnosis, were recorded on the questionnaire, whilst every participant was also asked to complete a standard health questionnaire. This was done to collect data on their general health status, medical history and current treatment. In addition, files of participants were reviewed and for those with a confirmed psychiatric diagnosis, this was recorded on the questionnaire with their current treatment. In the case of participants with hypertension, treatment, if any, as well as the number of times blood pressure readings were recorded in the previous six months was also noted.

The basic health questionnaire used in this study was an adjusted form of the standardized health questionnaire of SANLAM, a large insurance company. Permission was obtained from SANLAM for the use of this questionnaire. The criteria used for hypertension, increased body mass index (BMI) and increased waist circumference were as defined by the National Cholesterol Education Programme (NCEP). ${ }^{31}$ Measurements used for the statistical analysis were those done during the study.

\section{Statistical analysis}

All data was entered into a single database. As some of the data was descriptive in nature, results are provided as means with standard deviations, where appropriate. Categorical variables were compared using chi-square or Fisher's exact test, where applicable and differences between groups in terms of continuous variables were analyzed using Student's ttest. All statistical tests were two-sided and a significance level of 0.05 was used throughout. Statistical analyses were performed using Statistica 8 (Statsoft, 2007).

\section{Ethical considerations}

The study was conducted in accordance with the International Committee for Harmonization (ICH) Good Clinical Practice (GCP) guidelines and South African GCP guidelines as well as the Declaration of Helsinki (2000). The study protocol was submitted to and approved by the Committee for Human Research of the University of Stellenbosch (Ethics Number 07/10/238).

\section{Results}

We found no significant differences in demographic and physical variables between the participants with psychiatric disorders and those with other medical conditions (Table I). Differences in

\section{Table I: Differences in demographic variables and cardio-metabolic risk factors between participants followed up for psychiatric illness (Psychiatry Group) and other participants (General group).}

\begin{tabular}{|c|c|c|c|c|c|c|c|c|c|c|}
\hline \multicolumn{4}{|l|}{ Psychiatry group } & \multicolumn{7}{|l|}{ General group } \\
\hline Item & Mean & $n$ & $\%$ & Mean & $n$ & $\%$ & $x^{2}$ & $t$ & df & $p$ \\
\hline $\begin{array}{l}\text { Gender (Female) } \\
\text { Age (in years) } \\
\text { Abnormal BP }{ }^{1} \\
\text { Weight } \\
\text { Waist circumference (all) } \\
\text { Waist circumference (Male) } \\
\text { Waist circumference (Female) } \\
\text { Body Mass Index }\end{array}$ & $\begin{array}{l}42.9( \pm 11.1) \\
71.8( \pm 19.2) \\
90.6( \pm 16.1) \\
85.4( \pm 14.6) \\
93.9( \pm 16.2) \\
27.1( \pm 7.6)\end{array}$ & $\begin{array}{l}101 \\
101 \\
100 \\
101 \\
101 \\
39 \\
62 \\
101\end{array}$ & $\begin{array}{l}61 \\
30\end{array}$ & $\begin{array}{l}41.7( \pm 13.6) \\
69.9( \pm(21.7) \\
89.1( \pm 17.0) \\
83.2( \pm 13.2) \\
92.3( \pm 18.0) \\
26.9( \pm 8.0)\end{array}$ & $\begin{array}{l}100 \\
100 \\
100 \\
100 \\
99 \\
35 \\
64 \\
100\end{array}$ & $\begin{array}{l}65 \\
34\end{array}$ & $\begin{array}{l}0.28 \\
0.37\end{array}$ & $\begin{array}{l}0.57 \\
0.67 \\
0.66 \\
0.69 \\
0.52 \\
0.13\end{array}$ & \begin{tabular}{|l}
1 \\
199 \\
1 \\
199 \\
198 \\
72 \\
124 \\
199
\end{tabular} & $\begin{array}{l}0.60 \\
0.57 \\
0.54 \\
0.50 \\
0.51 \\
0.49 \\
0.60 \\
0.89\end{array}$ \\
\hline
\end{tabular}


Table II: Differences in monitoring of risk factors for cardio-metabolic disorders between participants followed up for psychiatric illness (Psychiatry Group) and other participants (General group).

\begin{tabular}{|c|c|c|c|c|c|c|c|c|c|c|}
\hline \multicolumn{4}{|l|}{ Psychiatry group } & \multicolumn{7}{|l|}{ General group } \\
\hline Item & Mean & $n$ & $\%$ & Mean & $n$ & $\%$ & $x^{2}$ & $t$ & $d f$ & $p$ \\
\hline $\begin{array}{l}\text { Previous } \mathrm{BP}^{1} \\
\text { Frequency of } \mathrm{BP}^{2} \\
\text { Hypertension } \\
\text { Record of weight in file }\end{array}$ & $0.48( \pm 1.29)$ & $\begin{array}{l}101 \\
101 \\
101 \\
101\end{array}$ & $\begin{array}{l}38.61 \\
15 \\
25.74\end{array}$ & $1.39( \pm 1.51)$ & $\begin{array}{l}100 \\
100 \\
100 \\
100\end{array}$ & $\begin{array}{l}86 \\
34 \\
68\end{array}$ & $\begin{array}{l}48.0 \\
9.99 \\
36.04\end{array}$ & -4.63 & $\begin{array}{l}1 \\
199 \\
1 \\
1\end{array}$ & $\begin{array}{l}<0.001 \\
<0.001 \\
0.002 \\
<0.001\end{array}$ \\
\hline
\end{tabular}

1. Previous blood pressure recording available in clinical notes

2. Frequency of blood pressure recording in the preceding 6 months

3. Diagnosis of hypertension noted in file

monitoring of risk factors between the groups (Table II) show that participants with psychiatric illness were significantly less likely to have a recording of previous BP, hypertension and weight in their clinical notes. Where the BP was monitored, it was monitored less frequently for the psychiatric group. No participants had their waist circumference recorded in their file. The results of the survey of the health care workers are presented in Tables III and IV. This shows that only 10\% of healthcare workers were aware that patients with SMI have reduced life expectancy, 73\% of healthcare workers believed that patients with SMI are aware of their cardio-metabolic risk and $60 \%$ of healthcare workers believed that reduced awareness in those with psychiatric illness results from poor insight. Only $18 \%$ of healthcare workers knew that patients with SMI were at increased risk of metabolic disorders and only $9 \%$ knew of these patients' increased risk for cardiovascular disease. A majority (76\%) of healthcare workers believed that patients with SMI were monitored for cardio-metabolic disease as often as the rest of the clinical population. Results of the "awareness of illness" section of the patient participant questionnaire are presented in Table V. It shows significant differences in awareness of risk of cardiovascular, metabolic and other medical disorders between participants with SMI and those without, with lower levels of awareness in the psychiatric population on all three counts.

\section{Table III: Results of health care worker questionnaire (True/False Section) $(n=22)$}

When we compare psychiatric patients to the general population, we find that they:

\begin{tabular}{|l|l|}
\hline Question & $\begin{array}{l}\text { Percentage (\%) of Health } \\
\text { Care workers who felt that } \\
\text { this statement was true }\end{array}$ \\
\hline $\begin{array}{l}\text { 1. Die earlier than the rest of the population } \\
\text { 2. Die earlier mostly as a result of suicide }\end{array}$ & 10 \\
$\begin{array}{l}\text { 3. Die prematurely due to medical disease } \\
\text { 4. Are aware of their increased risk for cardio- } \\
\text { metabolic disorders }\end{array}$ & 36 \\
$\begin{array}{l}\text { 5. Are not aware of their risk due to poor } \\
\text { insight rather than not being informed properly }\end{array}$ & 60 \\
\hline 1. Only if the response to question 4 was in the negative \\
\hline
\end{tabular}

Table IV: Results of the health care worker questionnaire (monitoring of disease) $(n=22)$

When we compare psychiatric patients to the general population, we find that they:

\begin{tabular}{|l|l|l|l|}
\hline Question & $\begin{array}{l}\text { Less often } \\
(\%)\end{array}$ & $\begin{array}{l}\text { As often } \\
(\%)\end{array}$ & $\begin{array}{l}\text { More often } \\
(\%)\end{array}$ \\
\hline Are at risk of metabolic disorder & 14 & 68 & 18 \\
\hline Are at risk of cardiovascular disorder & 23 & 68 & 9 \\
\hline $\begin{array}{l}\text { Should be monitored for metabolic/ } \\
\text { cardiovascular disease }\end{array}$ & 9 & 50 & 41 \\
\hline $\begin{array}{l}\text { Are monitored for metabolic/ } \\
\text { cardiovascular disease at this clinic }\end{array}$ & 10 & 76 & 14 \\
\hline
\end{tabular}

Table V: Results of the "awareness of illness" section of the patient participant questionnaire. Differences in disease awareness between participants followed up for psychiatric illness (Psychiatry Group) and other participants (General group)

\begin{tabular}{|c|c|c|c|c|c|c|c|c|c|c|}
\hline \multicolumn{4}{|l|}{ Psychiatry group } & \multicolumn{7}{|c|}{ General group } \\
\hline Item & Mean & $n$ & $\%$ & Mean & $n$ & $\%$ & $x 2$ & $t$ & $d f$ & $p$ \\
\hline $\begin{array}{l}\text { Cardiovascular disease } \\
\text { Metabolic disease } \\
\text { Other medical disorders }\end{array}$ & & $\begin{array}{l}101 \\
101 \\
101\end{array}$ & $\begin{array}{l}25.7 \\
9.9 \\
46.5\end{array}$ & & $\begin{array}{l}100 \\
100 \\
100\end{array}$ & $\begin{array}{l}47 \\
23.0 \\
83.0\end{array}$ & $\begin{array}{l}9.82 \\
6.28 \\
29.25\end{array}$ & & $\begin{array}{l}1 \\
1\end{array}$ & $\begin{array}{l}0.002 \\
0.01 \\
<0.001\end{array}$ \\
\hline
\end{tabular}




\section{Discussion}

This study was designed to determine whether there is similar comorbidity of SMI and risk factors for cardiometabolic disorders in a South African population to that reported in the literature from the developed world. The measurements chosen were blood pressure, waist circumference and BMI, as these are simple tests that can be done with minimal cost in a primary care setting. Although other tests, such as fasting glucose and fasting serum cholesterol would have been desirable, we decided against these for three reasons. Firstly, cost implications would probably prohibit the widespread use of these tests in all psychiatric patients in the developing world. ${ }^{16}$ Secondly, it was logistically impossible and unreliable to request all patients attending a clinic to fast, and thirdly, some studies suggest that simple measurements such as waist circumference have very high sensitivity for detecting patients at risk for cardio-metabolic illness. ${ }^{3 ; 8 ; 32}$

Our findings suggest that components of the metabolic syndrome are at least as prevalent in the mentally ill sample as in the general clinic sample, affecting about one third of either group. With only two out of five ATP III ${ }^{31}$ criteria for metabolic syndrome assessed, it cannot be stated that all of these patients definitely would have met criteria for metabolic syndrome, however if we consider the findings of Straker and co-workers ${ }^{32}$, it seems likely that most of these participants were at significant risk.

Interestingly, that waist circumference was only raised above the norm for females in both groups, whereas that for males in both groups was low. As we had no control group from the general population, it is difficult to interpret this result beyond saying that females who attend clinics in the Western Cape may be at increased risk of metabolic syndrome, whether they have psychiatric disorders or not. It should however be kept in mind that metabolic problems have been described in patients with schizophrenia who were not overweight. ${ }^{33}$

Furthermore, these findings may indicate that the prevalence of the risk factors is similar, but not greater, in the psychiatric population than in the rest of the clinical population. This is clearly different from studies such as CATIE, where metabolic syndrome was significantly more prevalent in the psychiatric population. ${ }^{12}$ This may reflect genetic or dietary differences and, at least to some extent, prescribing patterns. In the Western Cape, fluoxetine is by far the most prescribed antidepressant and first-generation antipsychotics are still used for the majority of patients who require antipsychotic medication. Fluoxetine and the firstgeneration antipsychotics seem to have a much lower propensity for inducing weight gain that some of the other antidepressants and many of the second generation antipsychotics.

As far as the diagnosis of cardio-metabolic risk factors goes, our study suggests that, although the prevalence of the risk factors was similar in the two groups, patients in the psychiatry group were far less likely to receive a diagnosis than patients in the general group. This finding should be interpreted with care, as it may only reflect the fact that the patients in the general group represent a selected group of individuals who had been diagnosed with a physical ailment in the first place. However, this seems unlikely in the light of the findings from other studies. ${ }^{1 ; 2 ; 10 ; 12}$ Furthermore, the known increase in risk amongst psychiatric patients should be cause for better monitoring in this population when compared to the rest of the population.

It is of great concern, although not altogether unexpected, to see the vast differences in general health monitoring of patients with SMI and the rest of the clinical population. Our results reconfirm findings from other parts of the globe showing that patients with SMI are less likely to be monitored and therefore less likely to be diagnosed with medical disorders such as hypertension. In fact, patients with SMI had their blood pressure measured on average less than once in the last six months, compared to three times for the rest of the clinical population. It should also be of concern that the waist circumference and BMI was not recorded for any single patient participant in either group. These are simple tools with high sensitivity that can be employed at even the most remote and poorly resourced clinics to identify those patients who are at risk of cardiometabolic disorders.

Our findings suggest that healthcare workers are not well informed of the risks that patients with SMI face with regards to cardio-metabolic disorders. What is also worrying is the large discrepancy between the perception of healthcare workers and the practical, day-to-day realities of patients who are followed up at a clinic. Healthcare workers believe that patients with psychiatric disorders are not being discriminated against and that they are being monitored as regularly as the rest of the clinical population, when this is clearly not the case. The prejudice may therefore not be conscious, but on an unconscious level, which makes it even more complex to address.

Although the prevalence of cardio-metabolic risk factors was similar between the psychiatry group and the general clinical population, the psychiatric population was far less likely to be aware of their risk. This was ascribed to "poor insight" by the healthcare workers, however our findings suggest that it may reflect the poor monitoring of the physical health of patients with SMI.

The last decade has seen a move to integrate services for psychiatric patients with the general health system, particularly on the primary care level. However, the realities of the South African health system are that mentally ill patients were diverted from previously dedicated community care systems to already hopelessly overburdened primary care clinics where they receive minimal attention. Although we strongly support the reintegration of mental health into the general medical system, we should not lose sight of the fact that patients with SMI represent a particularly vulnerable group who are likely to be marginalized and discriminated against, even by healthcare workers. ${ }^{24 ; 25 ; 30}$ Dedicated staff, who attend to the needs of the mentally ill within the larger primary care setting would, in our opinion, be a simple and workable solution to this problem.

Equal access to health care for all citizens is enshrined in the South African constitution. However, it seems that the system is failing patients with mental disorders. Because medical practice is becoming more compartmentalized, care should be taken that all patients, but particularly those with SMI, have a single healthcare worker who assumes 
responsibility for their holistic management. Lack of consensus over which health care professionals should take responsibility, paucity of funding for general medical care, prevention and health promotion for long term psychiatric patients all contribute to disparity in care for these patients. ${ }^{16}$ There is thus a critical need for psychiatrists and primary care professionals to increase awareness of and attention to the physical health problems of persons living with mental illness, including appropriate management of metabolic adverse events associated with psychiatric medications. All interested parties should be encouraged to become activists to combat stigma and discrimination and to also work against the demedicalization of treatment of mental health disorders. ${ }^{15}$

\section{Study limitations}

A reasonable sample size ( $\mathrm{n}=201$ ) was recruited and the researchers took steps to ensure that the sample was representative of the population under study. The two study groups were similar in respect of variables such as age and gender and were recruited from the same geographical area and served by the same resources. However, the generalisability of the findings is limited due to the fact that the full study population was recruited from a single clinic for a single, cross-sectional evaluation. Although unlikely, it is possible that services and medical practices may be very different at other primary care clinics in the Western Cape. Limitations in terms of the clinical variables should also be noted: a single, raised blood pressure reading should be interpreted with care and does not constitute a diagnosis of hypertension. Furthermore, only two of the criteria of the metabolic syndrome were assessed and conclusions about the prevalence of the metabolic syndrome in this cohort can, at best, be tentative.

\section{Conclusion}

Our study suggests that patients with SMI in South Africa are not monitored adequately in terms of their risk factors for cardio-metabolic disorders. Moreover, both patients and healthcare workers are largely unaware of the risk that patients with SMI face in this regard. Even though simple tools to assess risk are freely available, they are not used on a regular basis. Further training of primary health care workers, psychoeducation of patients and an ongoing anti-stigma campaign are needed to improve the situation, while serious consideration should be given to the wider availability of dedicated services for the mentally ill at the primary care level.

\section{Acknowledgments}

The authors would like to thank Ms. Karen Cloete for reviewing this manuscript.

\section{References}

1. Miller BJ, Paschall CB, Svendsen DP. Mortality and medical comorbidity among patients with serious mental illness. Psychiatric Services 2006;57: 1482-1487.

2. Nasrallah HA. An overview of common medical comorbidities in patients with schizophrenia. Journal of Clinical Psychiatry 2005;66: 34.

3. Bermudes RA, Keck PE, Welge JA. The prevalence of the metabolic syndrome in psychiatric inpatients with primary psychotic and mood disorders. Psychosomatics 2006;47: 491-497.

4. Fleischhacker WW, Cetkovich-Bakmas M, De Hert M, et al. Comorbid somatic illnesses in patients with severe mental disorders: Clinical, policy, and research challenges. Journal of Clinical Psychiatry 2008;69: 514-519.

5. Hennekens CH, Hennekens AR, Hollar D, et al. Schizophrenia and increased risks of cardiovascular disease. American Heart Journal 2005;150: 1115-1121.

6. Hennekens CH. Increasing global burden of cardiovascular disease in general populations and patients with schizophrenia. Journal of Clinical Psychiatry 2007;68: 4-7.

7. Norman R, Bradshaw D, Schneider M, et al. A comparative risk assessment for South Africa in 2000: Towards promoting health and preventing disease. Samj South African Medical Journal 2007; 97: 637-641.

8. Ntyintyane LM, Panz VR, Raal FJ, et al. Postprandial lipaemia, metabolic syndrome and LDL particle size in urbanised South African blacks with and without coronary artery disease. Qjm-An International Journal of Medicine 2008;101: 111-119.

9. van der Merwe MT, Pepper MS. Obesity in South Africa. Obesity Reviews 2006; 7: 315-322.

10. Bobes J, Arango C, Aranda P, et al. Cardiovascular and metabolic risk in outpatients with schizophrenia treated with antipsychotics Results of the CLAMORS Study. Schizophrenia Research 2007;90: 162-173.

11. Frayne SM, Halanych JH, Miller DR, et al. Disparities in diabetes care - Impact of mental illness. Archives of Internal Medicine 2005; 165: 2631-2638

12. Mcevoy JP, Meyer JM, Goff DC, et al. Prevalence of the metabolic syndrome in patients with schizophrenia: Baseline results from the Clinical Antipsychotic Trials of Intervention Effectiveness (CATIE) Schizophrenia Trial and comparison with national estimates from NHANES III. Schizophrenia Research 2005;80: 19-32.

13. Kemperman RFJ, Veurink M, van der Wal T, et al. Low essential fatty acid and B-vitamin status in a subgroup of patients with schizophrenia and its response to dietary supplementation. Prostaglandins Leukotrienes and Essential Fatty Acids 2006;74: 75-85.

14. McElroy SL, Kotwal R, Malhotra S, et al. Are mood disorders and obesity related? A review for the mental health professional. Journal of Clinical Psychiatry 2004;65: 634-651.

15. Newcomer JW, Sernyak MJ. Identifying metabolic risks with antipsychotics and monitoring and management strategies. J Clin Psychiatry 2007;68: el7.

16. Oosthuizen PP, Carey P, Emsley RA. Psychiatric Disorders and General Medical Conditions: Implications for the Clinician. Afr J Psychiatry 2008;1 1: 18-22.

17. Taylor V, MacQueen G. Associations between bipolar disorder and metabolic syndrome: A review. Journal of Clinical Psychiatry 2006;67: 1034-1041.

18. Isojarvi JIT, Rattya J, Myllyla VV, et al. Valproate, lamotrigine, and insulin-mediated risks in women with epilepsy. Annals of Neurology 1998;43: 446-451.

19. Joffe H, Cohen LS, Suppes T, et al. Longitudinal follow-up of reproductive and metabolic features of valproate-associated polycystic ovarian syndrome features: A preliminary report. Biological Psychiatry 2006;60: 1378-1381.

20. Lieberman JA, Stroup TS, Mcevoy JP, et al. Effectiveness of antipsychotic drugs in patients with chronic schizophrenia. New England Journal of Medicine 2005;353: 1209-1223.

21. Newcomer JW. Metabolic considerations in the use of 
antipsychotic medications: A review of recent evidence. Journal of Clinical Psychiatry 2007;68: 20-27.

22. Newcomer JW, Campos JA, Marcus RN, et al. A multicenter, randomized, double-blind study of the effects of aripiprazole in overweight subjects with schizophrenia or schizoaffective disorder switched from olanzapine. Journal of Clinical Psychiatry 2008;69: 1046-1056.

23. Stroup TS, Mcevoy JP, Swartz MS, et al. The National Institute of Mental Health Clinical Antipsychotic Trials of Intervention Effectiveness (CATIE) project: Schizophrenia trial design and protocol development. Schizophrenia Bulletin 2003;29: 15-31.

24. Diwayi, N. P. Mental Illness in Primary Care: A study to investigate nurses' knowledge of mental illness and attitudes. 2002. University of Cape Town. Ref Type: Thesis/Dissertation.

25. Hugo CJ, Boshoff DEL, Traut A, et al. Community attitudes toward and knowledge of mental illness in South Africa. Social Psychiatry and Psychiatric Epidemiology 2003;38: 715-719.

26. MaGPIe Research Group. General practitioners' perceptions of barriers to their provision of mental healthcare: a report on Mental Health and General Practice Investigation (MaGPIe). N Z Med J 2005; 118: 1222.

27. Mubbashar MH, Farooq S. Mental health literacy in developing countries. The British Journal of Psychiatry 2001;179: 75-7a.

28. Muir-Cochrane E. Medical co-morbidity risk factors and barriers to care for people with schizophrenia. Journal of Psychiatric and Mental Health Nursing 2006; 13: 447-452.

29. Seedat S, Stein DJ, Berk M, et al. Barriers to treatment among members of a mental health advocacy group in South Africa. Social Psychiatry and Psychiatric Epidemiology 2002;37: 483-487.

30. Steyn K, Levitt NS, Patel M, et al. Hypertension and diabetes: Poor care for patients at community health centres. Samj South African Medical Journal 2008;98: 618-622.

31. Expert Panel on Detection EaToHBCiA. Executive Summary of The Third Report of The National Cholesterol Education Program (NCEP) Expert Panel on Detection, Evaluation, And Treatment of High Blood Cholesterol In Adults (Adult Treatment Panel III). JAMA 2001;285: 2486-2497.

32. Straker D, Correll CU, Kramer-Ginsberg E, et al. Cost-effective screening for the metabolic syndrome in patients treated with second-generation antipsychotic medications. American Journal of Psychiatry 2005;162: 1217-1U10.

33. Ryan MCM, Collins P, Thakore JH. Impaired fasting glucose tolerance in first-episode, drug-naive patients with schizophrenia. American Journal of Psychiatry 2003; 160: 284-289. 